\title{
Food insufficiency among HIV-infected crack-cocaine users in Atlanta and Miami
}

\author{
Nicholas S Vogenthaler ${ }^{1, *}$, Craig Hadley ${ }^{2}$, Sarah J Lewis ${ }^{3}$, Allan E Rodriguez ${ }^{4}$, \\ Lisa R Metsch ${ }^{5}$ and Carlos del Rio ${ }^{6}$ \\ 'Division of Infectious Diseases, School of Medicine, Emory University, 69 Jesse Hill Jr. Drive - SE, Atlanta, GA \\ 30303, USA: ${ }^{2}$ Department of Anthropology, Emory University, Atlanta, GA, USA: ${ }^{3}$ School of Social Work, Barry \\ University, Miami Shores, FL, USA: ${ }^{4}$ Division of Infectious Diseases, Miller School of Medicine, University of \\ Miami, Miami, FL, USA: ${ }^{5}$ Department of Epidemiology and Public Health, Miller School of Medicine, University \\ of Miami, Miami, FL, USA: ' Hubert Department of Global Health, Rollins School of Public Health, Emory \\ University, Atlanta, GA, USA
}

Submitted 15 June 2009: Accepted 9 December 2009: First published online 15 January 2010

\begin{abstract}
Objective: To measure the occurrence and correlates of food insufficiency among HIV-infected crack-cocaine users in Atlanta and Miami, USA.

Design: Non-probability cross-sectional sample.

Setting: Inner-city hospitals in Atlanta and Miami.

Subjects: Two hundred and eighty-seven HIV-infected crack users.

Results: One-third (34\%) of respondents experienced food insufficiency within $30 \mathrm{~d}$ of interview. Increased odds of food insufficiency was associated with current homelessness (adjusted OR $=3 \cdot 78,95 \%$ CI 1·70, 8·41), living alone (adjusted $\mathrm{OR}=2 \cdot 85,95 \% \mathrm{CI} 1 \cdot 36,5 \cdot 98$ ), religious service attendance (adjusted $\mathrm{OR}=2 \cdot 34$, $95 \%$ CI $1 \cdot 02,5 \cdot 38$ ) and presence of health insurance (adjusted OR $=2 \cdot 41,95 \%$ CI $1 \cdot 06,5 \cdot 54$ ). Monthly income greater than \$US 600 (adjusted OR $=0 \cdot 19,95 \% \mathrm{CI}$ $0 \cdot 06,0.58$ ) was associated with decreased odds of food insufficiency, and less than weekly crack use was marginally associated with decreased odds of food insufficiency (adjusted OR $=0 \cdot 39,95 \%$ CI 0·13, 1·08).

Conclusions: Food insufficiency is very prevalent among HIV-infected urban crack-cocaine users in Atlanta and Miami. Correlates of food insufficiency confirm the social vulnerability of these individuals. Routine assessment for food insecurity should become a routine component of treatment and prevention programmes in at-risk populations.
\end{abstract}

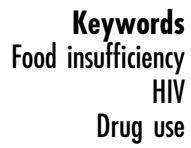

Food insecurity occurs when there is limited or uncertain availability of nutritionally adequate and safe foods or limited ability to acquire acceptable foods in socially acceptable ways ${ }^{,(1,2)}$. The national US Household Food Security Survey documented that $10.9 \%$ of US households, roughly 35.5 million people, were food insecure in 2006. One-third of food-insecure households experienced very low food security ${ }^{(1)}$. Food insufficiency is one aspect of the construct of food insecurity and refers to periods of time when individuals have involuntarily experienced reductions in dietary intake because of lack of social or economic resources ${ }^{(3)}$. Thus, food insufficiency implies the experience of food insecurity but the reverse is not true ${ }^{(4)}$. Food insufficiency is associated with poor physical and mental health, overweight status, depression and diabetes ${ }^{(5-8)}$. Despite these wellcharacterized associations, the prevalence and correlates of food insufficiency in HIV-infected individuals is underexplored.
Food insufficiency and HIV/AIDS participate in a vicious cycle that heightens the vulnerability to each condition ${ }^{(9)}$. International organizations have recognized this interplay by calling for improved integration of food and HIV/AIDS programming activities ${ }^{(10,11)}$. Emerging research has begun to explore food insufficiency's impact on HIV risk behaviour and outcomes ${ }^{(12-14)}$. Despite this recognition, food insufficiency remains a likely and under-appreciated barrier to HIV services and effective antiretroviral treatment ${ }^{(12)}$. Recently, food insufficiency has been connected to HIVassociated wasting $^{(15)}$, compromised antiretroviral adherence $^{(13,16)}$ and incomplete virologic HIV suppression ${ }^{(16)}$. Despite these provocative findings, investigations into the experience of food insufficiency and food insecurity among people living with HIV/AIDS outside the African continent remain sparse.

HIV-infected crack-cocaine users are a particularly vulnerable group. Their lives are often chaotic and complicated by poverty, crime, family dysfunction and violence ${ }^{(17,18)}$. 
Few crack-cocaine users effectively enter drug treatment ${ }^{(19)}$. Crack-cocaine use has been associated with failure to use outpatient care and with high-risk sexual behaviour ${ }^{(20,21)}$. Crack users are at increased risk for sexual transmission of HIV and may play an important role in sustaining the epidemic $^{(22)}$. The routine identification of food insecurity among HIV-infected crack-cocaine users represents an opportunity to engage these individuals in treatment services, positively impact their risk behaviours and prevent unnecessary negative health outcomes.

In reports to date, food insufficiency appears highly prevalent in North American HIV-infected individuals ${ }^{(15,16,23)}$. An improved understanding of the prevalence and predictive factors of food insufficiency within specific populations of HIV-infected individuals is necessary if we are to better identify those at risk for wasting, malnutrition, suboptimal adherence and other adverse health outcomes. We therefore examined the prevalence of and determinants of food insufficiency in a cross-sectional sample of HIVinfected crack users in Atlanta and Miami, USA.

\section{Methods}

\section{Study population and data collection}

Participants were recruited from the inpatient hospital wards at Grady Memorial Hospital in Atlanta, Georgia and Jackson Memorial Hospital in Miami, Florida. Structured interviews were administered to eligible participants upon their enrolment in a behavioural intervention study for sexually active HIV-infected crack users called Project HOPE (Hospital Visit is an Opportunity for Prevention and Engagement with HIV-positive Crack Users). Fourteen eligible individuals did not participate in the study. Five individuals declined enrolment and nine were medically incapable of participation. Participants provided written consent and were reimbursed \$US 25 for the interview. Interviewers collected interview data at hospital bedside using a Handheld-Assisted Personal Interview module. Collected data included information on sociodemographics, alcohol, drug use and clinical status. CD4 counts and viral loads were abstracted from participants' medical records, if available within $30 \mathrm{~d}$ before or after the interview date. The study was approved by the University of Miami and Emory University Institutional Review Boards and the Jackson Memorial Hospital and Grady Memorial Hospital Research Oversight Committees.

\section{Assessment of food insufficiency}

The primary dependent variable was food insufficiency. Food insufficiency was measured with a single item and respondents were asked: 'In the last 30 days was there any time when you didn't get anything, or barely anything, to eat for two or more days?' Although there is substantial debate in the literature over how to best measure food insecurity and food insufficiency, several studies have shown that single-item measures of food insufficiency and hunger have high face validity and are predictive of dietary, mental and physical health outcomes $^{(8,24-28)}$. Kaiser et al. showed food insufficiency and food insecurity, as measured by the US Household Food Security Scale (HFSS), to be significantly correlated ${ }^{(27)}$. Although recognized as a potential limitation of the current study, our single-item measure of food insufficiency was initially chosen for inclusion as a component of a broader assessment of respondent vulnerability that was included in the baseline survey. The experience this question captures is likely to overlap with food insecurity and may represent a severe level of food insecurity given its similarity to Question 12 in the HFSS, which is also a severe indicator of food insufficiency ${ }^{(1)}$.

\section{Categorization of covariates}

Covariates were chosen for evaluation based on known association with food insufficiency from prior studies or epidemiological plausibility of association, and are presented in Table 1 . The covariates for the study included age (continuous), gender (male/female), race/ethnicity (black, non-Hispanic; white, non-Hispanic; Hispanic), self-reported monthly income ( $\leq$ \$US100, \$US 100-600, $\geq$ \$US 600), education ( $\geq$ high school diploma or equivalent, $<$ high school diploma or equivalent), current employment (yes/ no), current homelessness (yes/no), incarceration within the previous 6 months (yes/no), presence of health insurance at the time of the interview (any/none), receipt of free meal services during the last month (yes/no), attendance at religious services during the last 6 months (yes/no), having ever used injection drugs (yes/no), daily alcohol use during the last 6 months (yes/no), crack-use intensity during the last 6 months (daily, weekly, less than weekly), current CD4 count ( $\leq 200$ cells $/ \mu \mathrm{l},>200$ cells $/ \mu \mathrm{l})$ and current viral load ( $\leq 400$ copies $/ \mathrm{ml},>400$ copies $/ \mathrm{ml}$ ).

\section{Statistical analysis}

Spearman's correlation and the $\chi^{2}$ test were used to examine bivariate associations between selected covariates. Next, multivariate logistic regression was used to identify factors independently associated with being food insufficient. Data are presented within categories as frequencies ( $n$ and \%) or as mean and standard deviation. The 0.05 level was chosen as the criterion for statistical significance and $P$ values less than $0 \cdot 10$ were considered marginally significant. The STATA statistical software package version 9 (StataCorp LP, College Station, TX, USA) was used for all statistical analyses.

\section{Results}

\section{Participant characteristics}

In total, 292 HIV-infected crack-cocaine users were enrolled and completed a baseline interview between 
Table 1 Selected characteristics of the study population: HIVinfected crack-cocaine users in Atlanta and Miami, USA, August 2006-January 2009

\begin{tabular}{|c|c|c|}
\hline Characteristic & $n$ & $\%$ \\
\hline \multicolumn{3}{|l|}{ Gender } \\
\hline Female & 153 & $53 \cdot 8$ \\
\hline Male & 134 & $46 \cdot 2$ \\
\hline \multicolumn{3}{|l|}{ Race/ethnicity } \\
\hline Black, non-Hispanic & 266 & $91 \cdot 4$ \\
\hline White, non-Hispanic & 17 & $5 \cdot 8$ \\
\hline Hispanic & 8 & $2 \cdot 8$ \\
\hline \multicolumn{3}{|l|}{ City } \\
\hline Atlanta & 172 & $58 \cdot 9$ \\
\hline Miami & 120 & $41 \cdot 1$ \\
\hline \multicolumn{3}{|l|}{ Monthly income } \\
\hline$\leq \$$ US 100 & 114 & 39.5 \\
\hline \$US $100-599$ & 107 & $37 \cdot 0$ \\
\hline$\geq \$$ US 600 & 68 & 23.5 \\
\hline \multicolumn{3}{|l|}{ Marital status } \\
\hline Single, never married & 192 & $65 \cdot 8$ \\
\hline Other & 100 & $34 \cdot 2$ \\
\hline \multicolumn{3}{|l|}{ Current homelessness } \\
\hline Yes & 129 & $44 \cdot 3$ \\
\hline No & 107 & $36 \cdot 4$ \\
\hline Missing & 56 & $19 \cdot 3$ \\
\hline \multicolumn{3}{|l|}{ Education } \\
\hline$<$ High school diploma & 154 & $52 \cdot 9$ \\
\hline$\geq$ High school diploma & 137 & $47 \cdot 1$ \\
\hline \multicolumn{3}{|l|}{ Employment } \\
\hline Unemployed & 282 & $96 \cdot 9$ \\
\hline Employed & 9 & $3 \cdot 1$ \\
\hline \multicolumn{3}{|l|}{ Live alone } \\
\hline Yes & 92 & 31.9 \\
\hline No & 196 & $68 \cdot 1$ \\
\hline \multicolumn{3}{|l|}{ Recent incarceration } \\
\hline Yes & 80 & $27 \cdot 5$ \\
\hline No & 184 & $63 \cdot 2$ \\
\hline Missing & 27 & $9 \cdot \overline{3}$ \\
\hline \multicolumn{3}{|l|}{ Health insurance } \\
\hline Any insurance & 140 & $48 \cdot 8$ \\
\hline None identified & 147 & $51 \cdot 2$ \\
\hline \multicolumn{3}{|l|}{ Free meals } \\
\hline Yes & 125 & $43 \cdot 0$ \\
\hline No & 164 & $56 \cdot 4$ \\
\hline \multicolumn{3}{|l|}{ Religious services } \\
\hline Yes & 181 & $62 \cdot 4$ \\
\hline No & 109 & $37 \cdot 6$ \\
\hline \multicolumn{3}{|l|}{ Injection drug use, ever } \\
\hline Yes & 65 & $22 \cdot 3$ \\
\hline No & 227 & $77 \cdot 7$ \\
\hline \multicolumn{3}{|l|}{ Daily alcohol } \\
\hline Yes & 63 & $21 \cdot 6$ \\
\hline No & 229 & $78 \cdot 4$ \\
\hline \multicolumn{3}{|l|}{ Crack-use intensity } \\
\hline Daily & 97 & $33 \cdot 2$ \\
\hline Weekly & 110 & $37 \cdot 7$ \\
\hline Less than weekly & 64 & 21.9 \\
\hline Missing & 21 & $7 \cdot 2$ \\
\hline
\end{tabular}

August 2006 and January 2009. Five participants did not answer the single-item question addressing food insufficiency and were therefore excluded from further analysis. Of the remaining respondents, 34\% ( $n$ 97) were categorized as food insufficient.

Selected characteristics of the respondents are shown in Table 1 . Mean age was 43 years, 54\% were female and $91 \%$ were black, non-Hispanic. Fifty-three per cent reported less than a high school diploma or equivalent.
Seventy-six per cent reported an income in the most recent month of less than \$US 600. Approximately half (44\%) of participants were homeless at the time of the interview. Twenty-eight per cent of participants had been incarcerated within the last 6 months. Current unemployment was nearly universal (97\%). One-half of participants (51\%) identified no form of health insurance, including Medicaid, Medicare, Veterans Benefits, AIDS Drug Assistance Program assistance, or private health insurance. Almost two-thirds (62\%) attended religious services at least once within the last 6 months. Forty-three per cent had received free meals within the last month. Daily crack-cocaine use was reported by $33 \%$ of respondents. Twenty-two per cent reported a history of ever using injection drugs, and $22 \%$ reported daily alcohol use.

\section{Bivariate correlates of food insufficiency and sociodemograpbic factors}

In unadjusted analysis, individuals who reported living in Atlanta, with lower self-reported monthly income, current homelessness, living alone, recent incarceration and increased intensity of crack use were more likely to experience food insufficiency (Table 2). Self-reported monthly income demonstrated an inverse dose-response relationship with food insufficiency, with increasing income associated with decreasing food insufficiency $(P=0 \cdot 014$, test for trend). Crack-use intensity also demonstrated a statistically significant test for trend, with progressive decrease in reported food insufficiency as crack-use intensity decreased $(P=0 \cdot 033)$.

\section{Bivariate correlations of food insufficiency and clinical status}

Clinical correlates of food insufficiency were examined in bivariate analysis only (Table 3 ). In this analysis, food insufficiency was associated with decreased likelihood of currently being on antiretroviral therapy regardless of CD4 count $(P=0 \cdot 013)$ and in those individuals with CD4 count $\leq 200$ cells $/ \mu$ l. There was a trend towards an association for both the time since diagnosis and having a missed HIV appointment in the last 6 months. Foodinsufficient individuals were no more likely to have received a referral to a nutritionist. Absolute CD4 count or viral load was not associated with food insufficiency. However, in the 120 individuals with available viral load measurements, food insufficiency was more common in those with viral load $>400$ copies $/ \mathrm{ml}$. Similarly, in the subgroup of those with a documented viral load who were currently on antiretroviral therapy ( $n$ 47), food insufficiency was not significantly associated, but was more common in those with viral load $>400$ copies $/ \mathrm{ml}$ (21\%) than in those with viral load $\leq 400$ copies/ml $(5 \%)$. Finally, although not significant $(P=0 \cdot 13)$, food insufficiency was more common in those who had never been in HIV care $(43 \%)$ than in those who had ever been in care $(32 \%)$. 
Table 2 Bivariate associations between food insufficiency and selected sociodemographic factors in the study population: HIVinfected crack-cocaine users in Atlanta and Miami, USA, August 2006-January 2009

\begin{tabular}{|c|c|c|}
\hline Characteristic & Food insufficiency (\%) & $P$ value \\
\hline Gender & & 0.50 \\
\hline Female & $32 \cdot 0$ & \\
\hline Male & $35 \cdot 8$ & \\
\hline Race/ethnicity & & $0 \cdot 36$ \\
\hline Black, non-Hispanic & $33 \cdot 7$ & \\
\hline White, non-Hispanic & $41 \cdot 2$ & \\
\hline Hispanic & $12 \cdot \overline{5}$ & \\
\hline City & & 0.003 \\
\hline Atlanta & $40 \cdot 7$ & \\
\hline Miami & $24 \cdot 2$ & \\
\hline Monthly income & & 0.039 \\
\hline$\leq$ US $\$ 100$ & $40 \cdot 5$ & \\
\hline \$US $100-599$ & 34.9 & \\
\hline$\geq \$$ US 600 & $22 \cdot 1$ & \\
\hline Marital status & & $0 \cdot 21$ \\
\hline Single, never married & $36 \cdot 4$ & \\
\hline Other & $29 \cdot 0$ & \\
\hline Current homelessness & & $<0.001$ \\
\hline Yes & $48 \cdot 4$ & \\
\hline No & $22 \cdot 1$ & \\
\hline Education & & $0 \cdot 84$ \\
\hline$<$ High school diploma & $34 \cdot 4$ & \\
\hline$\geq$ High school diploma & $33 \cdot 3$ & \\
\hline Employment & & 0.97 \\
\hline Unemployed & $33 \cdot 9$ & \\
\hline Employed & $33 \cdot 3$ & \\
\hline Live alone & & $<0.001$ \\
\hline Yes & $52 \cdot 8$ & \\
\hline No & $25 \cdot 0$ & \\
\hline Recent incarceration & & 0.046 \\
\hline Yes & $43 \cdot 0$ & \\
\hline No & $30 \cdot 8$ & \\
\hline Health insurance & & 0.77 \\
\hline Any insurance & $33 \cdot 1$ & \\
\hline None identified & $34 \cdot 7$ & \\
\hline Free meals & & $0 \cdot 46$ \\
\hline Yes & $36 \cdot 3$ & \\
\hline No & $32 \cdot 1$ & \\
\hline Religious services & & $0 \cdot 71$ \\
\hline Yes & $34 \cdot 8$ & \\
\hline No & $32 \cdot 7$ & \\
\hline Injection drug use, ever & & 0.55 \\
\hline Yes & $36 \cdot 9$ & \\
\hline No & $32 \cdot 9$ & \\
\hline Daily alcohol & & $0 \cdot 30$ \\
\hline Yes & $39 \cdot 3$ & \\
\hline No & $32 \cdot 3$ & \\
\hline Crack-use intensity & & 0.08 \\
\hline Daily & $40 \cdot 4$ & \\
\hline Weekly & $36 \cdot 1$ & \\
\hline Less than weekly & $23 \cdot 4$ & \\
\hline
\end{tabular}

\section{Multivariate modelling of predictors of food insufficiency}

In adjusted analysis (Table 4), the association of housing status and income with food insufficiency status persisted. Current homelessness had the strongest association with increased odds of food insufficiency (adjusted OR $=3 \cdot 78$, $95 \%$ CI $1 \cdot 70,8 \cdot 41)$. Living alone was also strongly associated with food insufficiency (adjusted OR $=2 \cdot 85,95 \%$ CI $1 \cdot 36,5 \cdot 98)$. Interestingly, both church attendance (adjusted OR $=2 \cdot 34,95 \%$ CI $1 \cdot 02,5 \cdot 38)$ and presence of
Table 3 Bivariate associations between food insufficiency and selected clinical characteristics in the study population: HIV-infected crack-cocaine users in Atlanta and Miami, USA, August 2006January 2009

\begin{tabular}{|c|c|c|}
\hline Characteristic & $\begin{array}{c}\text { Food } \\
\text { insufficiency } \\
(\%)\end{array}$ & $P$ value \\
\hline Current ART, if CD4 count $<200$ cells $/ \mu$ l & & 0.035 \\
\hline Yes & $15 \cdot 6$ & \\
\hline No & $35 \cdot 9$ & \\
\hline Current ART, if CD4 count $<350$ cells $/ \mu \mathrm{l}$ & & $0 \cdot 011$ \\
\hline Yes & $15 \cdot 6$ & \\
\hline No & $36 \cdot 4$ & \\
\hline Ever on ART & & 0.49 \\
\hline Yes & $39 \cdot 0$ & \\
\hline No & $34 \cdot 4$ & \\
\hline Ever in HIV care & & $0 \cdot 13$ \\
\hline Yes & $31 \cdot 8$ & \\
\hline No & $42 \cdot 6$ & \\
\hline HIV care in last 6 months & & $0 \cdot 16$ \\
\hline No visit & $46 \cdot 2$ & \\
\hline One or more visits & $32 \cdot 6$ & \\
\hline Missed appointment in last 6 months & & 0.064 \\
\hline Yes & $36 \cdot 2$ & \\
\hline No & $24 \cdot 1$ & \\
\hline Time since diagnosis & & 0.093 \\
\hline$\leq 1$ year & $29 \cdot 4$ & \\
\hline$>1$ year & $38 \cdot 8$ & \\
\hline Nutritionist referral & & $0 \cdot 86$ \\
\hline Yes & $33 \cdot 3$ & \\
\hline No & $31 \cdot 9$ & \\
\hline Viral load & & 0.078 \\
\hline$\leq 400$ copies $/ \mathrm{ml}$ & $8 \cdot 7$ & \\
\hline$>400$ copies $/ \mathrm{ml}$ & $25 \cdot 8$ & \\
\hline
\end{tabular}

ART, antiretroviral therapy.

health insurance (adjusted OR $=2 \cdot 41,95 \%$ CI $1 \cdot 06,5 \cdot 54$ ) were associated with increased odds of food insufficiency, although neither was notable on bivariate analysis. Self-reported monthly income of $\geq \$$ US 600 was protective compared with the reference of $\leq \$$ US 100 (adjusted $\mathrm{OR}=0 \cdot 19,95 \% \mathrm{CI} 0 \cdot 06,0 \cdot 58$ ). Compared with a reference of daily crack use, less than weekly crack use was marginally associated with decreased odds of food insufficiency (adjusted OR $=0 \cdot 39,95 \%$ CI $0 \cdot 13,1 \cdot 08$ ). In this model, all other variables described in Table 1 were not associated with reported food insufficiency.

\section{Discussion}

The current study is the first we know of to examine the prevalence and correlates of food insufficiency among HIV-infected crack users. Thirty-three per cent of respondents experienced food insufficiency in the $30 \mathrm{~d}$ prior to the interview. The experience of food insufficiency was associated with housing status, both current homelessness and living alone. Food insufficiency was also associated with some measures of social support, as indicated by the relationship with health insurance status and church attendance. We also found that higher selfreported monthly income and a decreasing frequency of 
Table 4 Multivariate logistic regression model of factors associated with food insufficiency in the study population: HIV-infected crack-cocaine users in Atlanta and Miami, USA, August 2006-January 2009

\begin{tabular}{|c|c|c|}
\hline Characteristic & Adjusted OR & $95 \% \mathrm{Cl}$ \\
\hline Age (per year) & 0.97 & $0.92,1.03$ \\
\hline Gender (female $v$. male) & $2 \cdot 03^{*}$ & $0.91,4.53$ \\
\hline Current homelessness (yes v. no) & $3 \cdot 78^{\star \star \star}$ & $1 \cdot 70,8 \cdot 41$ \\
\hline Living alone (yes $v$. no) & $2 \cdot 85^{\star \star \star}$ & $1.36,5 \cdot 98$ \\
\hline \multicolumn{3}{|l|}{ Monthly income } \\
\hline$\leq \$ \cup S 100$ & Reference & \\
\hline \$US $100-599$ & 0.87 & $0.37,2 \cdot 02$ \\
\hline$\geq \$$ US 600 & $0 \cdot 19^{\star * *}$ & $0.06,0.58$ \\
\hline \multicolumn{3}{|l|}{ Crack-use intensity } \\
\hline Daily & Reference & \\
\hline Weekly & $1 \cdot 17$ & $0.51,2 \cdot 67$ \\
\hline Less than weekly & $0 \cdot 39^{\star}$ & $0 \cdot 13,1.08$ \\
\hline Religious service attendance (yes $v$. no) & $2 \cdot 34^{\star \star}$ & $1 \cdot 02,5 \cdot 38$ \\
\hline Health insurance status (yes $v$. no) & $2 \cdot 41^{\star \star}$ & $1 \cdot 06,5 \cdot 54$ \\
\hline
\end{tabular}

Significance: ${ }^{*} P<0 \cdot 10,{ }^{* *} P<0 \cdot 05,{ }^{* * *} P<0 \cdot 01$.

crack use protected one from food insufficiency. No other social or economic variables were consistently associated with the experience of food insufficiency.

The prevalence of food insufficiency in our study was three times the prevalence of food insecurity in the general US population in 2006, which was estimated to be $10 \cdot 9 \%^{(1)}$. The study estimate was also markedly higher than the food insecurity prevalence estimates in the states in which the study was conducted: $12.6 \%$ and $8.9 \%$ for Georgia and Florida, respectively ${ }^{(1)}$. Only $1.4 \%$ of adult respondents in the general US population sample reported not eating for a whole day in the last 12 months. This HFSS item was most comparable to our single-item assessment of food insufficiency and highlights the severity of the indicator used in the present study. The food insufficiency prevalence in our HIV-positive population was similar in magnitude to the few other North American studies that have evaluated food insecurity in HIV-infected individuals. In Vancouver, $48 \%$ of survey respondents participating in the British Columbia Drug Treatment Program were noted to be food insecure ${ }^{(23)}$. In San Francisco, $49 \%$ of a well-characterized cohort of homeless or marginally housed HIV-infected individuals were food insecure ${ }^{(16)}$. Lastly, from Miami and perhaps most comparable to this population, $61 \%$ of a community-based cohort of HIV-positive drug users reported having gone for more than a day without having eaten food during the previous month ${ }^{(15)}$.

The strongest predictor of food insufficiency was current homelessness. Homeless individuals had almost four times greater risk of being food insufficient than those with housing. Similarly, Normen et al. noted a greater than twofold increased risk in food insecurity in those with unstable housing in British Columbia ${ }^{(23)}$. Interestingly, living alone was also independently identified as an important correlate of food insufficiency. Although living alone has been identified as a risk factor in other studies ${ }^{(29,30)}$, the exact meaning of this variable in this heavily homeless population is unclear. Both homeless and housed individuals identified as living alone. In a stratified analysis by living alone status, homelessness was a risk factor in those reporting living alone (adjusted $\mathrm{OR}=28 \cdot 2,95 \% \mathrm{CI} 3 \cdot 1,255 \cdot 5)$, but not in those reporting living with others (adjusted $\mathrm{OR}=2 \cdot 29,95 \%$ CI $0 \cdot 86$, 6.14). Certain housing arrangements, in particular those with other individuals, may protect one from food insecurity in the setting of homelessness.

In addition, income continued to play a significant role in the experience of food insufficiency, especially in this population almost all of whom lived below the national poverty line. Self-reported monthly income over \$US 600 was the most protective risk factor noted in the current study. The significant trend inversely associating food insufficiency and monthly income was unexpected at this level of poverty. The lack of a notable association with annual income and the dose-response relationship noted with monthly income suggests that even in heavily impoverished populations, small increments in income and short-term income variability may be important in protecting against the experience of food insufficiency. Income source may play an important role in protection from food insufficiency through mechanisms of social support not purely mediated by income, although such data were not available for further exploration.

The association of crack-use intensity and food insufficiency has not previously been explored and little literature exists on the more general topic of drug use and food insecurity. One study comparing food security status among drug-using and non-drug-using Hispanic women in Connecticut reported no association between particular drug-use pattern and food security status ${ }^{(31)}$. Similarly, in a study of drug-using HIV-positive individuals where crack use was common (55\% of participants), no relationship between drug-use pattern and food security status was reported ${ }^{(15)}$. In our study, intensity of crack use showed a marginally significant stepwise pattern of association with food insufficiency. This relationship argues for the benefit of harm reduction strategies in reducing crack use among 
HIV-positive individuals and its plausible benefit in concomitantly reducing food insufficiency risk.

Two rather unexpected findings emerged from the multivariable analysis. Religious service attendance and presence of health insurance were associated with increased risk of food insufficiency. One plausible explanation for the association with religious service attendance is the important role of religious organizations in provision of social support. In this population, $50 \cdot 3 \%$ of religious service attendees reported receiving free meals in the last month, while only $31.0 \%$ of those who did not attend such services reported the same (Pearson $\left.\chi^{2}=11 \cdot 8, P=0 \cdot 003\right)$, suggesting that food insufficiency may motivate religious service attendance. Participants were more likely to have health insurance if they reported higher monthly income and if they were not homeless. When health insurance was present, the majority of respondents in our study identified Medicaid as the insurer. The Medicaid enrolment process may represent an important opportunity for assessment and alleviation of food insecurity. These findings may help clinicians and outreach workers identify locations and moments where food insecurity can be assessed and resources mobilized to alleviate the condition.

Little is known about the association of food insecurity and its impact on clinical outcomes in HIV-infected individuals. A single cross-sectional study has noted an association between food insecurity and lack of viral suppression $^{(16)}$. In those on therapy in the present study, there was a trend towards an association between food insufficiency and lack of viral suppression to $\leq 400$ copies $/ \mathrm{ml}$. We did not have additional information on medication regimen, time on therapy or adherence. Food insufficiency was also associated with decreased likelihood of being on antiretroviral therapy when such therapy would have been indicated based on CD4 count. Food-insufficient individuals were also marginally significantly more likely to miss a clinic appointment in the last 6 months. The bivariate associations between food insufficiency and clinical data in our study are exploratory, but suggestive. Additional research is needed to explore the impact of food insecurity on entry into care, use of antiretroviral therapy and likelihood of viral suppression. If emerging findings are confirmed, the alleviation of food insufficiency will clearly be an essential and modifiable component of comprehensive HIV care.

There are several limitations to our study. The selection of participants from the hospitalized setting limits the generalizability of the results. Second, the single-item measurement of food insufficiency does not reflect the full range or severity of food insecurity that may be experienced in this population. Given initial survey constraints in this difficult-to-assess population, we opted to use a measure that was quick to use. We may have underestimated the occurrence of food insufficiency by not using a scaled measure, which would have given respondents more opportunity to identify this experience. Despite the limitations of the single question measure, it is worth noting that previous studies have noted high correlation between single-item measures of food insufficiency and scaled measures ${ }^{(27)}$. Finally, the study was cross-sectional and therefore we are unable to determine a causal association between the correlates and presence of food insufficiency. Additional research is needed to expand our understanding of the presence and severity of food insecurity among individuals with HIV. Furthermore, longitudinal research could clarify the role of short-term variation in income and of changes in housing status on the durability of food insufficiency.

In conclusion, food insufficiency is a common experience in the lives of HIV-infected crack users. Current homelessness and severe poverty appear to be the most important correlates of food insufficiency. Small incremental improvements in income, housing status and social support may be critical in stabilizing and reducing the prevalence of food insufficiency in this population. Additional community and clinic resources should be directed towards identifying the presence of food insufficiency in at-risk HIV-positive individuals. Additional research is needed to explore the persistence of food insecurity over time in this population and the potential adverse impact of food insecurity on HIV-relevant health behaviours and clinical outcomes. Food insecurity is a modifiable entity and should be more widely assessed in the context of comprehensive HIV care.

\section{Acknowledgements}

Sources of funding: This study was supported in part by the National Institutes of Health/National Institute of Drug Abuse (grant DAO17612-01A2), the National Institutes of Health/National Institute of Allergy and Infectious Diseases Emory Center for AIDS Research (grant 2P30AI050409), and the University of Miami Developmental Center for AIDS Research (grant P30AI073961). Conflict of interest declaration: None. Authorship responsibilities: study design C.d.R. and L.R.M.; study implementation - C.d.R. and L.R.M.; data analysis - N.S.V.; write-up - N.S.V.; critical review of manuscript - C.H., A.E.R., S.J.L., C.d.R. and L.R.M.

\section{References}

1. Nord M, Andrews M \& Carlson S (2007) Household Food Insecurity in the United States, 2006. Economic Research Report no. ERR-49. Washington, DC: US Department of Agriculture, Economic Research Service.

2. Carlson SJ, Andrews MS \& Bickel GW (1999) Measuring food insecurity and hunger in the United States: development of a national benchmark measure and prevalence estimates. J Nutr 129, 2 S Suppl., 510S-516S.

3. Panel to Review the US Department of Agriculture's Measurement of Food Insecurity and Hunger (2006) Food Insecurity and Hunger in the United States: An Assessment 
of the Measure. Washington, DC: National Research Council, Committee on National Statistics, Division of Behavioral and Social Sciences and Education.

4. Hadley C, Galea S, Nandi V et al. (2008) Hunger and health among undocumented Mexican migrants in a US urban area. Public Health Nutr 11, 151-158.

5. Vozoris NT \& Tarasuk VS (2003) Household food insufficiency is associated with poorer health. J Nutr 133, 120-126.

6. Seligman HK, Bindman AB, Vittinghoff E et al. (2007) Food insecurity is associated with diabetes mellitus: results from the National Health Examination and Nutrition Examination Survey (NHANES) 1999-2002. J Gen Intern Med 22, 1018-1023.

7. Heflin CM, Siefert K \& Williams DR (2005) Food insufficiency and women's mental health: findings from a 3-year panel of welfare recipients. Soc Sci Med 61, 1971-1982.

8. Alaimo K, Olson CM \& Frongillo EA Jr (2001) Low family income and food insufficiency in relation to overweight in US children: is there a paradox? Arch Pediatr Adolesc Med 155, 1161-1167.

9. Gillespie S \& Kadiyala S (2005) HIV/AIDS and Food and Nutrition Security: From Evidence to Action. Washington, DC: International Food Policy Research Institute.

10. Seume-Fosso E, Rajabiun S, Cogill B et al. (2004) HIV/AIDS: A Guide For Nutritional Care and Support. Washington, DC: Food and Nutrition Technical Assistance.

11. World Food Programme (2003) Programming in the Era of AIDS: WPF's Response to HIV/AIDS. Rome: World Food Programme.

12. Rollins N (2007) Food insecurity - a risk factor for HIV infection. PLoS Med 4, 1576-1577.

13. Weiser S, Wolfe W, Bangsberg D et al. (2003) Barriers to antiretroviral adherence for patients living with HIV infection and AIDS in Botswana. J Acquir Immune Defic Syndr 34, 281-288.

14. Weiser SD, Leiter K, Bangsberg DR et al. (2007) Food insufficiency is associated with high-risk sexual behavior among women in Botswana and Swaziland. PLoS Med $\mathbf{4}$, 1589-1597.

15. Campa A, Yang Z, Lai S et al. (2005) HIV-related wasting in HIV-infected drug users in the era of highly active antiretroviral therapy. Clin Infect Dis 41, 1179-1185.

16. Weiser SD, Frongillo EA, Ragland K et al. (2009) Food insecurity is associated with incomplete HIV RNA suppression among homeless and marginally housed HIVinfected individuals in San Francisco. J Gen Intern Med 24, 14-20.
17. Sterk CE, Dolan K \& Hatch S (1999) Epidemiological indicators and ethnographic realities of female cocaine use. Subst Use Misuse 34, 2057-2072.

18. Boyd CJ \& Mieczkowski T (1990) Drug use, health, family and social support in 'crack' cocaine users. Addict Behav 15, 481-485.

19. Siegal HA, Falck RS, Wang J et al. (2002) Predictors of drug abuse treatment entry among crack-cocaine smokers. Drug Alcohol Depend 68, 159-166.

20. Metsch LR, McCoy HV, McCoy CB et al. (1999) Use of health care services by women who use crack cocaine. Women Health 30, 35-51.

21. Campsmith ML, Nakashima AK \& Jones JL (2000) Association between crack cocaine use and high-risk sexual behaviors after HIV diagnosis. J Acquir Immune Defic Syndr 25, 192-198.

22. McCoy CB, Metsch LR, Inciardi JA et al. (1996) Sex, drugs, and the spread of HIV/AIDS in Belle Glade, Florida. Med Anthropol Q 10, 83-93.

23. Normen L, Chan K, Braitstein P et al. (2005) Food insecurity and hunger are prevalent among HIV-positive individuals in British Columbia, Canada. J Nutr 135, 820-825.

24. Alaimo K, Briefel RR, Frongillo EA Jr et al. (1998) Food insufficiency exists in the United States: results from the third National Health and Nutrition Examination Survey (NHANES III). Am J Public Health 88, 419-426.

25. Alaimo K, Olson CM \& Frongillo EA (2002) Family food insufficiency, but not low family income, is positively associated with dysthymia and suicide symptoms in adolescents. J Nutr 132, 719-725.

26. Alaimo K, Olson CM, Frongillo EA Jr et al. (2001) Food insufficiency, family income, and health in US preschool and school-aged children. Am J Public Health 91, 781-786.

27. Kaiser LL, Melgar-Quinonez H, Townsend MS et al. (2003) Food insecurity and food supplies in Latino households with young children. J Nutr Educ Behav 35, 148-153.

28. Siefert K, Heflin CM, Corcoran ME et al. (2004) Food insufficiency and physical and mental health in a longitudinal survey of welfare recipients. J Health Soc Behav 45, 171-186.

29. Lee JS \& Frongillo EA Jr (2001) Factors associated with food insecurity among US elderly persons: importance of functional impairments. J Gerontol B Psychol Sci Soc Sci 56, S94-S99.

30. Quine S \& Morrell S (2006) Food insecurity in communitydwelling older Australians. Public Health Nutr 9, 219-224.

31. Himmelgreen DA, Pérez-Escamilla R, Segura-Millán S et al. (1998) A comparison of the nutritional status and food security of drug-using and non-drug-using Hispanic women in Hartford, connecticut. Am J Phys Anthropol 107, 351-361. 